\title{
UHMWPE fibre-based composites: Prestress-induced enhancement of impact properties
}

\author{
Adnan Fazal, Kevin S. Fancey* \\ School of Engineering, University of Hull, Hull HU6 7RX, United Kingdom
}

\begin{abstract}
The impact properties of continuous unidirectional UHMWPE fibre-reinforced polyester resin composites have been investigated, to elucidate the effects of prestress on energy absorption characteristics. Prestress within composite samples was produced by subjecting the UHMWPE fibres to a creep load, which was then released prior to moulding. From Charpy impact tests, these viscoelastically prestressed samples absorbed $\sim 20 \%$ more energy than their control (unstressed) counterparts, with some batches reaching $30-40 \%$. Generally, whether prestress is created through elastic or viscoelastic means, fibre-matrix debonding is known to be a major energy absorption mechanism in this type of composite, but this was not evident in the current study. Instead, evidence of debonding at the skin-core interface within the UHMWPE fibres was found, the skin regions possessing lower stiffness and longer term viscoelastic activity. Skin-core debonding appears to have a significant energy absorbing role within the prestressed samples and we believe it is a previously unrecognised mechanism.
\end{abstract}

Keywords: A. Polymer-matrix composites (PMCs); B. Impact behaviour; D. Mechanical testing; Viscoelasticity.

*Tel: +44-1482-465071; fax: +44-1482-466664.

E-mail address: k.s.fancey@hull.ac.uk

\section{Introduction}

Viscoelastically prestressed polymeric matrix composites (VPPMCs) provide improved mechanical performance over equivalent composites without prestress. Using Charpy impact testing, VPPMC samples have been found to absorb typically 25-30\% more impact energy than their control (unstressed) counterparts, with some samples reaching increases of 50\% [1-6]. Tensile tests [7] have demonstrated increases in strength, modulus and energy absorption exceeding 15\%,30\% and $40 \%$ respectively; also three-point bend tests [8] have shown flexural modulii to be $\sim 50 \%$ greater than corresponding control samples. 
VPPMC production requires polymeric fibres to be subjected to tensile (viscoelastic) creep; the creep load is then released before the fibres are moulded into a matrix. After matrix solidification, the strained fibres (in residual tension) continue to attempt viscoelastic recovery, thereby producing compressive stresses within the matrix. This state of prestress can also be obtained with elastically prestressed PMCs (EPPMCs), the required prestress being produced by maintaining an elastic tensile strain on the fibres whilst the matrix cures. For unidirectional continuous fibre-reinforced composites, improvements in EPPMC mechanical properties [9-11] are comparable to those of VPPMCs. In EPPMCs however, fibre length, orientation and spatial distribution are restricted by the application of fibre tension during matrix curing, thereby compromising fibre and mould geometries for more complex situations. Also, the matrix (being polymeric) may undergo localised creep at fibre-matrix interface regions, in response to the compressive stresses imposed by the fibres: hence the prestress effect in an EPPMC could deteriorate with time [3]. In contrast, accelerated ageing studies have demonstrated no deterioration in VPPMC mechanical (Charpy impact) performance over a duration equivalent to 20 years at a constant $40^{\circ} \mathrm{C}$ ambient [5].

To date, the main body of VPPMC research has been based on prestress provided by nylon 6,6 fibres [1-8]. Nevertheless, other researchers have successfully demonstrated VPPMCs based on bamboo and, although flexural modulii were increased by only $12 \%$, flexural toughness was improved by $28 \%$ [12]. Most recently, we have found increases of 20-40\% in flexural modulus from VPPMCs based on ultra-high molecular weight polyethylene (UHMWPE) fibres [13]. This paper reports the first findings from Charpy impact tests on UHMWPE fibre-based VPPMCs and our results lead to a previously unrecognised energy absorption mechanism being identified.

\section{Background}

With tensile strength and modulus values of $2.6 \mathrm{GPa}$ and $87 \mathrm{GPa}$ respectively, UHMWPE fibres are 44 times stronger and >20 times stiffer than nylon 6,6 fibres [14] used in earlier VPPMC studies. Moreover, within the composites community, there is a significant interest in UHMWPE fibre reinforcement, especially in terms of impact protection [15]. Thus the successful demonstration of enhanced impact performance from UHMWPE fibre VPPMCs could provide the groundwork for new directions in VPPMC technology.

Previous Charpy impact studies on nylon 6,6 fibre VPPMCs [1-5] ultimately led to the conclusion that impact energy absorption from prestress may arise from: (i) matrix compression impeding crack propagation, (ii) matrix compression attenuating dynamic overstress effects, (iii) residual fibre tension causing a more collective response to external loads and (iv) residual shear stresses at the fibre-matrix interface regions promoting energy absorbing fibre debonding (delamination) over transverse fracture [5]. Recent findings [6] suggest that (iv) is the principal mechanism, i.e. prestress-enhanced residual shear stresses between fibres and matrix are triggered by externally imposed shear stresses (during the impact process) to promote fibre-matrix debonding over transverse fracture. This mechanism has also been observed in glass fibre EPPMCs [10]. Therefore, UHMWPE fibre VPPMCs may be expected to exhibit similar impact fracture characteristics. 
Gel-spun UHMWPE fibres are, however, structurally more complex than nylon 6,6 fibres, the former being considered to possess skin-core properties. The skin is suggested to consist of low molecular weight fragments and solvent excluded during crystallisation [16,17] or as an unconstrained layer around a constrained core [18]. Etching experiments [19] have revealed evidence of contraction-induced stresses during crystallisation within the core but not in the skin. Moreover, X-ray diffraction studies with a single Dyneema fibre have identified monoclinic phase material occurring mostly in the skin, possibly from plastic deformation in this region [20]. Thus Refs [16-20] indicate that the skin may possess greater ductility and lower stiffness than the core.

After releasing an appropriate creep load, UHMWPE fibres have been shown to produce a viscoelastic recovery force; but the force reaches a maximum value followed by a gradual decline in output with time [13]. This is in contrast with equivalent findings from nylon 6,6 fibres, which show a progressive increase in force output with time [21]. We suggested in Ref. [13] that the rise and fall in force output may emanate from two competing mechanisms: this could arise from skin-core interactions within the fibres, caused by differences in viscoelastic properties between skin and core regions.

If this hypothesis is correct, then evidence of skin-core effects should be observable in fractured VPPMC samples following impact testing. In addition, we would expect longer term monitoring of the recovery force to show a progressive decrease towards a non-zero output level. This would represent a state of equilibrium existing between skin and core regions. To gain a further understanding of skin-core effects, this paper addresses both aspects, by (i) investigating the Charpy impact test characteristics of UHMWPE fibre-based VPPMCs and (ii) updating the measured UHMWPE fibre viscoelastic recovery force output to determine whether a constant output value is reached in the longer term.

\section{Experimental}

\subsection{Composite sample production}

As with earlier studies involving Charpy impact evaluation [1-6], open casting provided the simplest composite sample production method. Also in common with previous work, mechanical evaluation necessitated the comparison of VPPMC 'test' samples with unstressed 'control' counterparts. To ensure no differences between test and control samples (other than prestress effects), each batch required simultaneous production of test and control samples.

Materials and moulding procedures were similar to those employed for flexural stiffness evaluation [13] and are summarised here. The UHMWPE fibre was Dyneema SK60, supplied by Goodfellow Cambridge Ltd., UK. This was a continuous multifilament untwisted yarn comprising 1600 filaments (fibres), with $12 \mu \mathrm{m}$ mean filament diameter (supplier specification). In common with earlier nylon fibre-based VPPMC processing [1-8], the UHMWPE fibres required annealing to remove manufacturinginduced residual stresses and provide suitable viscoelastic creep-recovery characteristics. To produce one batch, two lengths of yarn (designated test and control) were simultaneously annealed (unconstrained) at $120^{\circ} \mathrm{C}$ for $0.5 \mathrm{~h}$ in a fan-assisted oven.

A bespoke stretching rig [6-8,13] was then used to subject the test yarn to a $24 \mathrm{~h}$ creep load of $1.3 \mathrm{GPa}$, whilst the control yarn was positioned (unconstrained) in close proximity for exposure to the same ambient conditions $\left(19.5-21.0^{\circ} \mathrm{C}\right)$. On releasing the 
creep load, both yarns were cut to appropriate lengths and brushed into flat ribbons (to separate the fibres) ready for moulding.

For the matrix, a clear-casting polyester resin was used as previously $[6,13]$, i.e. Cray Valley Norsodyne E9252, mixed with 1\% MEKP catalyst, supplied by CFS Fibreglass supplies, UK. Room temperature gel time was $\sim 0.25 \mathrm{~h}$ and demoulding could be performed after $2 \mathrm{~h}$. Open casting of unidirectional continuous fibre composite samples was achieved with two aluminium moulds and completed within $0.5 \mathrm{~h}$ of the stretching operation. Each mould had a $10 \mathrm{~mm}$ wide channel for casting a strip of test and control materials simultaneously from the same resin mix. Following demoulding, the composite strips were each cut into five equal lengths and held under a weighted steel strip for $24 \mathrm{~h}$ to prevent any stress-induced sample distortion.

Each batch consisted of five test and five control samples, the sample dimensions being $80 \times 10 \times 3.2 \mathrm{~mm}$ and were stored at room temperature $\left(19-22^{\circ} \mathrm{C}\right)$ prior to impact testing. A total of 30 batches were produced, all with a fibre volume fraction, $V_{\mathrm{f}}$, of $3.6 \%$.

\subsection{Charpy impact testing of composites}

A Ceast Resil 25 Charpy machine with $7.5 \mathrm{~J}$ hammer was used for impact testing at 3.8 $\mathrm{ms}^{-1}$, operating in accordance with BS EN ISO 179. In previous Charpy-based studies using nylon fibre in open-cast polyester matrix samples [1-6], the fibres tended to settle towards the bottom of the mould prior to curing. This was also observed in UHMWPE fibre composite cross-sections at 3.6\% $V_{\mathrm{f}}$ [13]. Thus all impact tests were conducted by mounting samples with the fibre-rich side facing away from the pendulum hammer. A diagram of this configuration has been previously published [1-3].

Three batches (i.e. 15 test and 15 control samples) were each impact tested under ambient conditions $\left(20-21^{\circ} \mathrm{C}\right)$ at a span setting, $L$, of 60 and $24 \mathrm{~mm}$. These $L$ settings corresponded to BS EN ISO 179 Specimen Types 2 and 3 respectively. This testing procedure was performed over five periods (24-1008 h) after moulding, to determine any short-term age-related effects. Following testing, fractured samples were selected for analysis, principally by scanning electron microscopy (SEM), to identify possible failure mechanisms.

\subsection{Fibre-based investigations}

As reported in Section 2, initial findings from a viscoelastic recovery force experiment led to speculation on skin-core behaviour within the fibres [13]. Full details of the procedure are given in Ref. [13], but essentially this involved subjecting a loop of annealed UHMWPE yarn to a $24 \mathrm{~h}$ creep load of $1.36 \mathrm{GPa}$. On releasing the creep load, the yarn immediately recovered its elastic strain. The loop, with its remaining viscoelastic strain, was then transferred to a bespoke force measurement rig. Here, the yarn, initially in a loose state, progressively tightened (through viscoelastic recovery) to a fixed strain, until a force output could begin to be monitored. The experiment has continued to run and, in the current work, the force output monitoring period has increased 5-fold, i.e. from $2000 \mathrm{~h}$ in Ref. [13] to $10000 \mathrm{~h}$. In accordance with the earlier work, all measurements were recorded at $20.9 \pm 1.0^{\circ} \mathrm{C}$.

Fibre annealing conditions were established through creep-recovery strain investigations and a small reduction in tensile strength $(<7 \%)$ was observed, compared with as-received yarn [13]. Although this treatment $\left(120^{\circ} \mathrm{C}\right.$ in air) was required to 
improve viscoelastic properties, oxidation could have been possible under these conditions [22,23]. Nevertheless, the short exposure time $(0.5 \mathrm{~h})$ compared with published findings at $120^{\circ} \mathrm{C}$ [23] suggest that oxidation should be negligible. To confirm this, annealing effects were also investigated in the current work by energydispersive X-ray analysis (EDX) to detect the possible presence of oxidation. Here, samples of as-received and annealed fibres were mounted on graphite supports and scanned (principally) for oxygen at $0.5249 \mathrm{keV}$ ( $\mathrm{K} \alpha$ radiation).

\section{Results and discussion}

\subsection{Charpy impact tests}

Table 1 summarises the impact energy data. Some batches show the test samples absorbing 30-40\% more energy than their control counterparts. For the two span settings, statistical hypothesis testing (5\% significance level) shows no difference between overall mean increases in energy absorbed by the test samples, i.e. the average increase from both span settings is $\sim 20 \%$. In absolute terms, energy absorption is 30$40 \%$ higher for both test and control groups when the span is increased to $60 \mathrm{~mm}$. These observations are in contrast with Charpy data from similar $\left(3.3 \% V_{\mathrm{f}}\right)$ nylon 6,6based fibre VPPMCs, where energy absorption in absolute terms dropped by 40-60\% at $60 \mathrm{~mm}$ span and the increase in energy absorbed by test samples was $40 \%$ at $24 \mathrm{~mm}$, but effectively zero at $60 \mathrm{~mm}$ span [6]. These disparities between UHMWPE and nylon 6,6 fibre-based composites suggest significant differences in the role of energy absorption mechanisms.

Table 1. Impact test results from composite sample batches: 5 (prestressed) test and 5 (unstressed) control samples per batch. For each span, 15 batches were tested. SE is the standard error of the mean.

\begin{tabular}{|c|c|c|c|c|c|c|c|c|}
\hline \multirow{3}{*}{$\begin{array}{c}\text { Age } \\
\text { (hours) }\end{array}$} & \multicolumn{4}{|l|}{24 mm span } & \multicolumn{4}{|l|}{$60 \mathrm{~mm}$ span } \\
\hline & \multicolumn{2}{|c|}{ Mean impact energy $\left(\mathrm{kJm}^{-2}\right)$} & \multirow{2}{*}{$\begin{array}{l}\text { Increase in } \\
\text { energy } \\
(\%)\end{array}$} & \multirow{2}{*}{$\begin{array}{l}\text { Mean increase } \\
\text { in energy } \\
(\% \pm S E)\end{array}$} & \multicolumn{2}{|c|}{ Mean impact energy $\left(\mathrm{kJm}^{-2}\right)$} & \multirow{2}{*}{$\begin{array}{l}\text { Increase in } \\
\text { energy } \\
(\%)\end{array}$} & \multirow{2}{*}{$\begin{array}{l}\text { Mean increase } \\
\text { in energy } \\
(\% \pm \mathrm{SE})\end{array}$} \\
\hline & Test $\pm \mathrm{SE}$ & Control \pm SE & & & Test $\pm S E$ & Control $\pm S E$ & & \\
\hline \multirow[t]{3}{*}{24} & $43.34 \pm 3.73$ & $33.32 \pm 1.43$ & 30.09 & $24.14 \pm 7.11$ & $41.75 \pm 1.54$ & $38.21 \pm 3.10$ & 9.27 & $21.25 \pm 9.27$ \\
\hline & $30.35 \pm 2.83$ & $27.59 \pm 1.75$ & 9.97 & & $42.57 \pm 2.26$ & $37.03 \pm 3.09$ & 14.98 & \\
\hline & $37.35 \pm 3.75$ & $28.22 \pm 1.45$ & 32.35 & & $46.83 \pm 5.40$ & $33.57 \pm 3.13$ & 39.49 & \\
\hline \multirow[t]{3}{*}{96} & $32.97 \pm 1.21$ & $28.18 \pm 2.22$ & 16.99 & $17.93 \pm 6.81$ & $46.23 \pm 5.24$ & $39.89 \pm 3.52$ & 15.92 & $15.47 \pm 5.72$ \\
\hline & $34.77 \pm 1.97$ & $32.60 \pm 1.96$ & 6.64 & & $39.10 \pm 3.47$ & $37.11 \pm 2.43$ & 5.35 & \\
\hline & $32.68 \pm 1.92$ & $25.11 \pm 1.18$ & 30.17 & & $39.12 \pm 3.59$ & $31.26 \pm 1.51$ & 25.15 & \\
\hline \multirow[t]{3}{*}{168} & $32.98 \pm 1.31$ & $30.34 \pm 0.48$ & 8.73 & $14.47 \pm 4.78$ & $46.25 \pm 5.50$ & $40.50 \pm 4.20$ & 14.21 & $23.97 \pm 5.62$ \\
\hline & $30.19 \pm 1.73$ & $27.27 \pm 1.47$ & 10.72 & & $44.22 \pm 4.45$ & $33.08 \pm 2.20$ & 33.69 & \\
\hline & $30.17 \pm 1.63$ & $24.34 \pm 0.83$ & 23.96 & & $39.34 \pm 2.96$ & $31.73 \pm 2.39$ & 24.01 & \\
\hline \multirow[t]{3}{*}{336} & $29.67 \pm 1.29$ & $23.75 \pm 0.99$ & 24.93 & $21.66 \pm 1.64$ & $54.05 \pm 6.69$ & $46.87 \pm 3.81$ & 15.34 & $26.01 \pm 8.04$ \\
\hline & $30.78 \pm 1.68$ & $25.66 \pm 1.15$ & 19.99 & & $47.59 \pm 4.61$ & $39.35 \pm 4.33$ & 20.93 & \\
\hline & $28.41 \pm 0.58$ & $23.67 \pm 1.40$ & 20.05 & & $52.59 \pm 4.07$ & $37.10 \pm 3.76$ & 41.76 & \\
\hline \multirow[t]{3}{*}{1008} & $29.80 \pm 2.20$ & $23.36 \pm 1.10$ & 27.57 & $20.04 \pm 3.78$ & $34.07 \pm 4.49$ & $31.81 \pm 1.57$ & 7.09 & $27.61 \pm 10.73$ \\
\hline & $32.21 \pm 1.12$ & $27.57 \pm 0.52$ & 16.83 & & $39.31 \pm 3.29$ & $29.69 \pm 2.49$ & 32.42 & \\
\hline & $28.63 \pm 0.85$ & $24.74 \pm 0.35$ & 15.72 & & $49.78 \pm 4.46$ & $34.71 \pm 2.32$ & 43.31 & \\
\hline Mean $\pm S E$ & $32.29 \pm 1.85$ & $27.05 \pm 1.22$ & $19.37 \pm 2.16$ & & $44.19 \pm 4.13$ & $36.13 \pm 2.92$ & $22.31 \pm 3.28$ & \\
\hline
\end{tabular}

Fig. 1 shows typical impact-tested samples and, for comparison, nylon 6,6 fibrebased samples from Ref. [6]. In all cases, compared with the hinged-break nylon fibre 
samples, the UHMWPE samples were completely fractured due to the fibres being more brittle. At $24 \mathrm{~mm}$ span, the vertical cracks away from the fracture site are similar for both UHMWPE and nylon fibre samples; these occur mainly at the anvil shoulder locations, as the Charpy hammer bends the sample into a ' $\mathrm{V}$ ' shape during impact. For the UHMWPE samples at $60 \mathrm{~mm}$ span however, there is more opportunity for specimen deflection, hence the greater prominence of vertical cracks as the sample becomes ' $U$ ' shaped during impact. The nylon fibre samples show fewer vertical cracks at $60 \mathrm{~mm}$ span, as the relatively low modulus fibres allow sample fracture characteristics to be dominated by the (brittle) matrix. In Ref [6], multiple vertical cracking was only observed with higher $V_{\mathrm{f}}$ values at this span. These observations lead us to suggest that the greater number of (energy absorbing) vertical cracks in the UHMWPE samples are responsible for the $30-40 \%$ increase in $\mathrm{kJm}^{-2}$ values from both test and control samples at the $60 \mathrm{~mm}$ span setting in Table 1 . These multiple cracks occur at a lower $V_{\mathrm{f}}$ than with the nylon case, as the much greater stiffness of UHMWPE fibres reduces the influence of matrix characteristics. This fibre stiffness effect may also relate to the increase in energy absorption from prestress effects being maintained at $60 \mathrm{~mm}$ span in Table 1, an effect only observed from nylon fibre samples at higher $V_{\mathrm{f}}$ in Ref. [6].

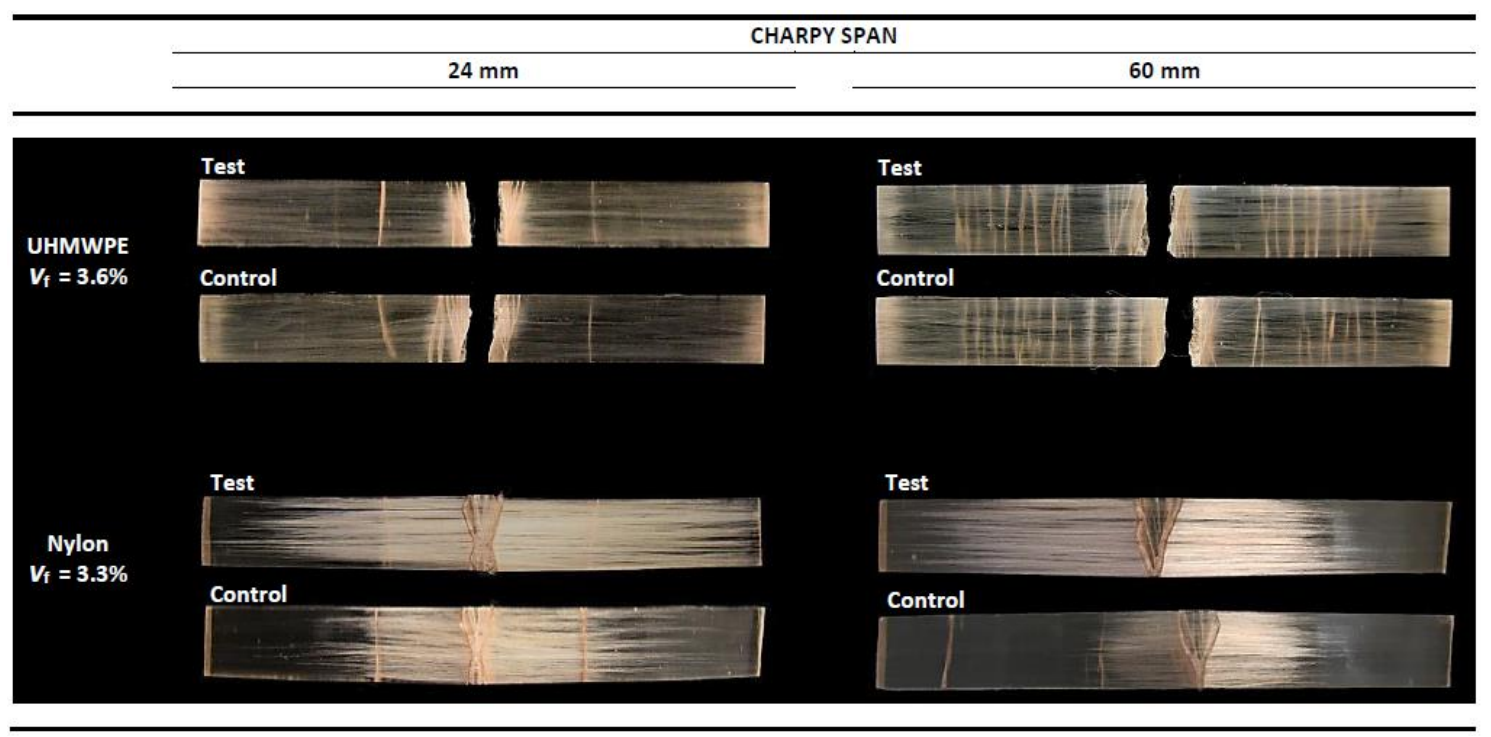

Fig. 1. Typical UHMWPE fibre-based composite test (prestressed) and control (unstressed) samples after impact testing. For comparison, equivalent nylon 6,6 fibre-based samples are also shown from Ref. [6].

Of major interest in Fig. 1 is that in contrast with the nylon 6,6 samples, no significant fibre-matrix debonding can be observed in the UHMWPE samples. As reported in Section 2, prestress-induced residual shear stresses at the fibre-matrix interface regions promote energy absorbing fibre debonding over transverse fracture. This explains the greater debonded area in the nylon fibre test samples compared with control counterparts, but the corresponding UHMWPE fibre test and control samples show no differences in fracture characteristics. Here, we suggest that there is an equivalent mechanism, but the debonding is not visible in Fig. 1, since it occurs between skin and core regions within the UHMWPE fibres. 


\subsection{Fibre inspection and analysis}

Fig. 2 shows optical micrograph cross-sections from the central area of typical test and control samples. Although there are no discernible differences between these samples, a wide range of fibre sizes and shapes (some appearing to be bundles of filaments) are dispersed within the matrix. Following impact testing, Fig. 3 shows representative SEM fracture cross-sections. Although fibre pull-out with clear separation from the matrix can be seen in the control samples, there appears to be a layer of residual fibre material that has coated the pull-out cavities in the test samples, i.e. evidence of core-skin debonding (cohesive failure). Moreover, UHMWPE strands (fibrils) can be observed in Fig. 3, these being more evident in the test samples, where they emanate from the edges of the pull-out cavities. Therefore, these fibrils must originate from the fibre skin regions. The SEM fracture section from a control sample in Fig. 4 supports this view: here, this fractured (but otherwise intact) fibre clearly shows a core region surrounded by a more ductile skin from which fibrils are formed during the impact process.

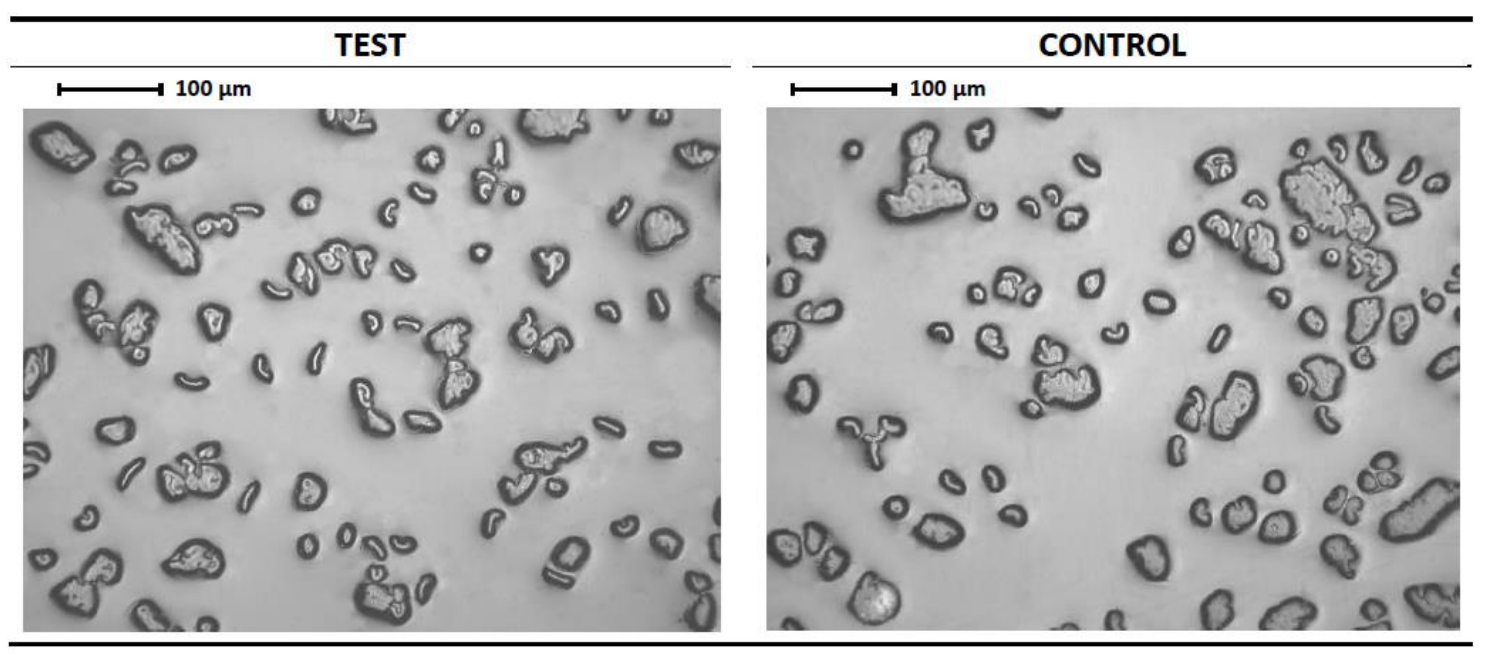

Fig. 2. Representative optical micrograph (polished) sections taken from the central areas of test and control samples, showing UHMWPE fibre cross-sectional geometries and their dispersion within the matrix.

As reported in Section 3.3, an EDX analysis was also performed on fibre samples. No significant levels of oxygen within the annealed or as-received fibres could be found. Moreover, at the highest levels of sensitivity, there were no differences between outputs from each sample that might indicate the smallest increase in oxygen from annealing. Thus although annealing causes a small reduction in fibre tensile strength [13], we conclude that there are no chemically-based changes to the fibres.

\subsection{Recovery force and time-dependent behaviour}

Fig. 5 shows the viscoelastic recovery force from UHMWPE yarn in terms of axial stress-time output, updated to $10000 \mathrm{~h}$. Also shown for comparison is the output from nylon 6,6 yarn data, which grows towards a limiting value of $12 \mathrm{MPa}$ [21]. In contrast 
with the nylon data, the UHMWPE output climbs to a maximum value at $\sim 8 \mathrm{~h}$, followed by a gradual decline with time; however, from $\sim 3000 \mathrm{~h}$, this levels off at $12-13 \mathrm{MPa}$.

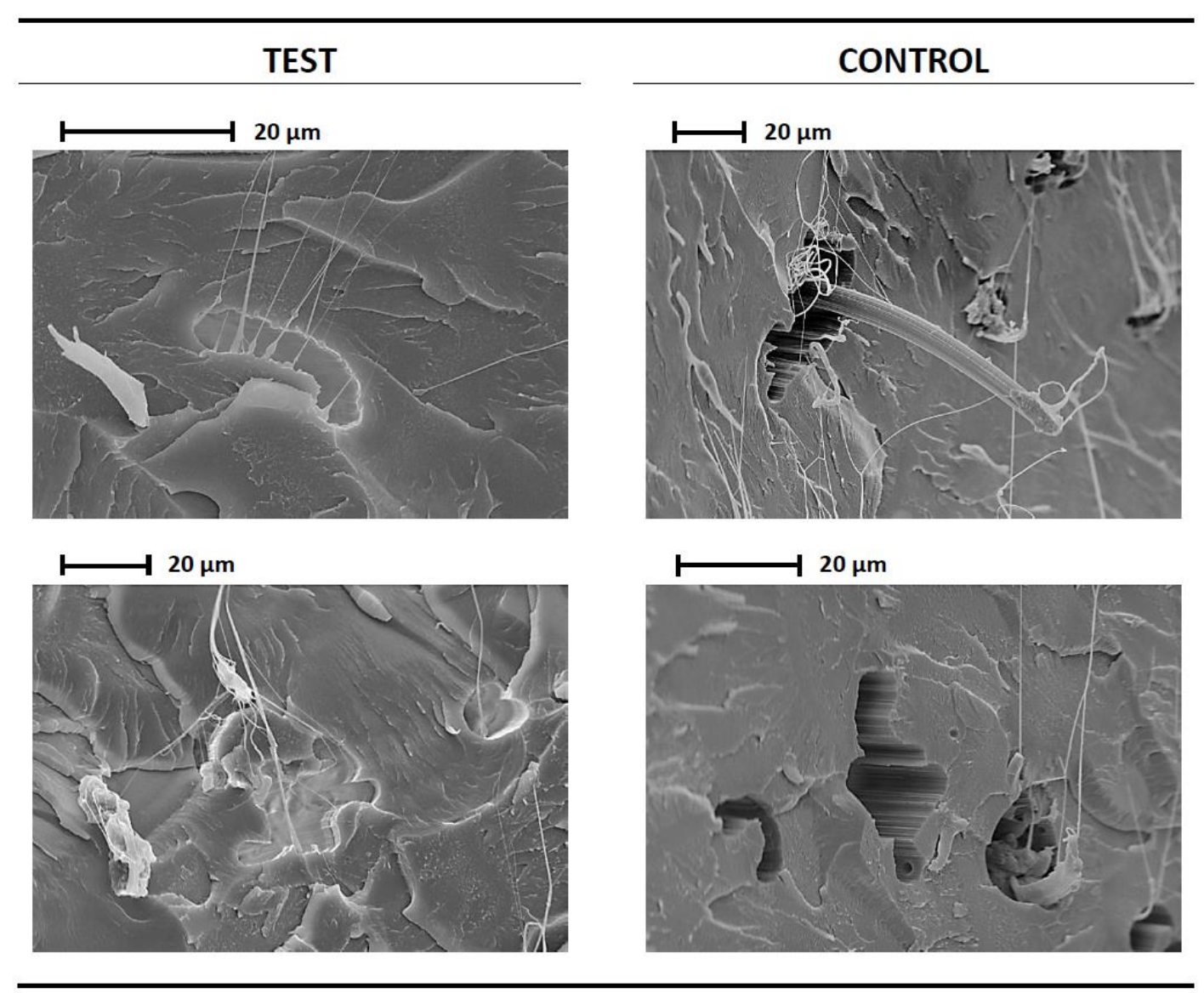

Fig. 3. SEM images of typical fracture surfaces from test and control samples after impact testing. Similar features were observed across impact fracture surfaces for both Charpy span settings.

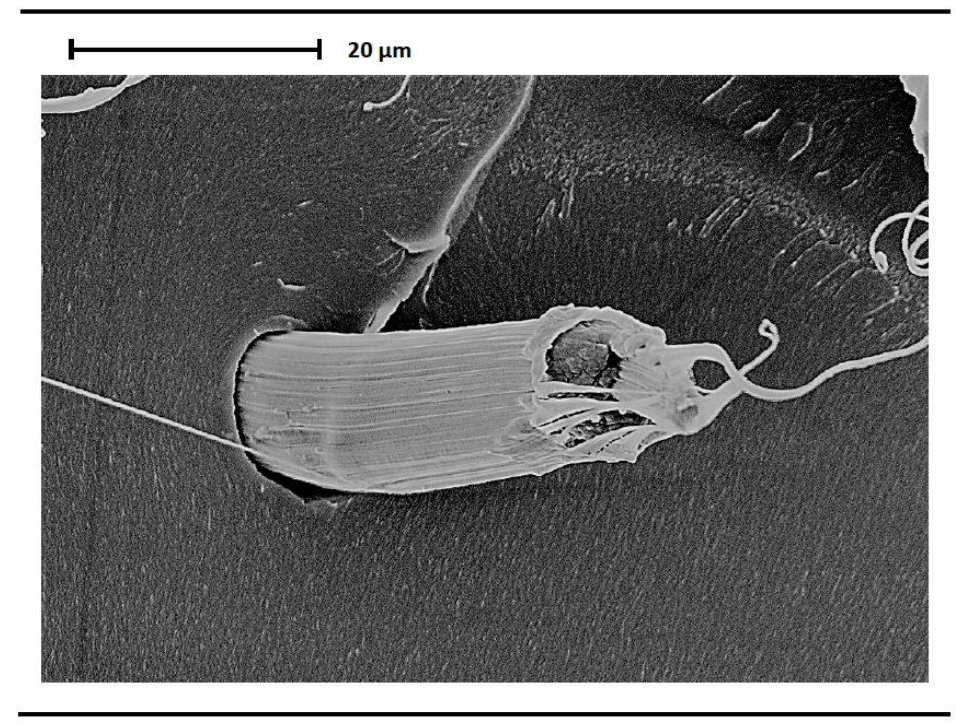

Fig. 4. SEM image from the fracture surface of a control sample, showing clear evidence of the skincore structure in a UHMWPE fibre. 


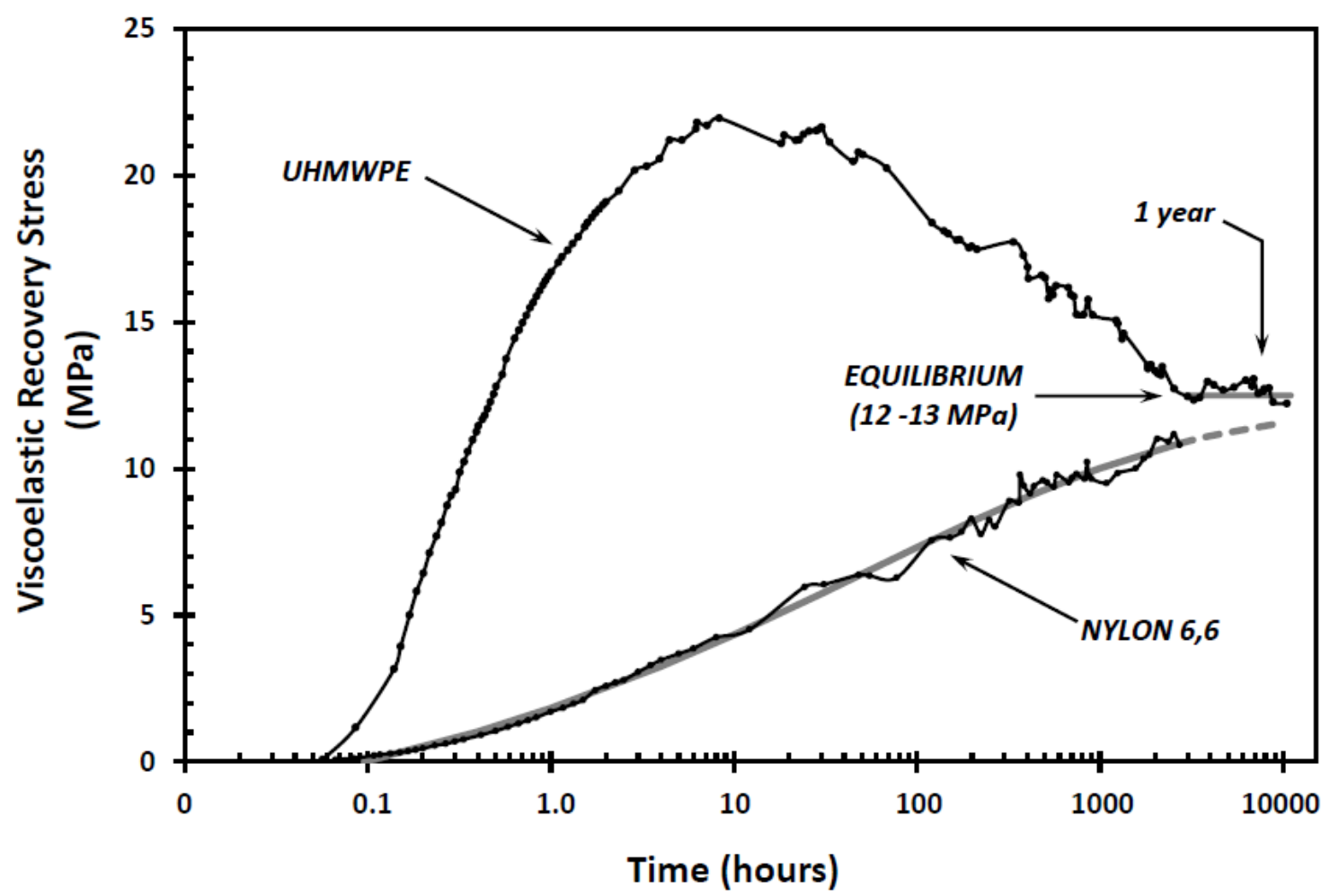

Fig. 5. Viscoelastic recovery force in terms of axial stress output (force relative to total cross-sectional area of the fibres) for the UHMWPE yarn (from 1.36 GPa, $24 \mathrm{~h}$ creep), updated from $2000 \mathrm{~h}$ [13] to $10000 \mathrm{~h}$. Also shown for comparison are data and curve-fit from Ref. [21] for nylon 6,6 yarn (from $0.32 \mathrm{GPa}, 24 \mathrm{~h}$ creep).

In Ref. [13], we proposed that the fibre core regions are stiffer and possess shorter time constants for viscoelastic activity. These core regions thus cause a rapid build-up of force output within the first $8 \mathrm{~h}$, as they attempt viscoelastic retraction (at fixed strain). The rate of force build-up progressively diminishes as viscoelastic energy stored within the cores becomes depleted through force generation and possible energy transfer to the skin regions. At $\sim 8 \mathrm{~h}$, longer term viscoelastic activity from the skin regions starts to dominate; however, the (less stiff) skin cannot maintain the coregenerated force magnitude, hence recovery force gradually decreases with time. We also proposed that a state of equilibrium would eventually exist between the skin and core regions, leading to a constant non-zero output level. This is now evident from the updated plot in Fig. 5. Moreover, evidence of the proposed differences in mechanical characteristics between skin and core regions can be clearly seen in Fig. 4 .

It should be noted that the impact energy data in Table 1 show no evidence of deterioration with sample age (24-1008 h), but in Fig. 5 there is a decline in recovery force output of $\sim 30 \%$ over the same period. This apparent discrepancy can be explained by considering that Fig. 5 shows the fibre axial force output, whereas prestress mechanisms within a VPPMC depend on shear stress transfer between fibres and matrix. Therefore, prestress in a VPPMC is determined by the viscoelastic recovery characteristics of the fibre skin regions. This supports our earlier explanation in Ref. [13] to account for a similar observation made with flexural stiffness measurements. 


\subsection{Implications for VPPMCs}

Although our current work highlights the significance of skin-core interactions within UHMWPE fibres, further investigations would be required to understand the implications for long-term viscoelastic activity (over many years) and how this might affect subsequent VPPMC performance. Such investigations would require accelerated ageing experiments through time-temperature superposition principles, similar to those adopted for nylon 6,6 fibre-based VPPMCs [4,5].

In contrast with the uniform size and shape of nylon 6,6 fibres [7] however, gelspun UHMWPE fibre cross-sections have no such uniformity, as evident from Fig. 2. The fibres have varying cross-sectional areas, with filaments having sub-structures of macrofibrils, these also possessing varying sizes, being typically $0.5-2 \mu \mathrm{m}$ diameter [24]. Although there appears to be little relevant information published on skin-core behaviour, skin-related effects might be expected to be more significant for fibre structures and sub-structures with smaller section areas [13]. Thus we can speculate that long-term viscoelastic mechanisms within a UHMWPE fibre-based VPPMC could be influenced by the typical cross-sectional size and size distribution of the fibres under consideration. Since the skin-core characteristics from other gel-spun UHMWPE fibre grades may differ from the material studied in this work (Dyneema SK60), their possible effects on VPPMC performance would require further investigation.

\section{Conclusions}

Charpy impact testing (at $24 \mathrm{~mm}$ and $60 \mathrm{~mm}$ span settings) and longer term measurements of fibre viscoelastic recovery force output have been used to investigate viscoelastically generated prestress in UHMWPE fibre-based composites. The main findings are as follows:

(i) Viscoelastically generated prestress increased impact energy absorption by typically $20 \%$, with some batches reaching $30-40 \%$. Although fibre-matrix debonding is known to be a major energy absorption mechanism in EPPMCs and VPPMCs, this was not evident in the current study. There is, however, evidence of debonding at the skin-core interface within the UHMWPE fibres during impact and this appears to have a significant energy absorbing role in the prestressed composite samples. We believe that this is a previously unrecognised energy absorption mechanism.

(ii) Although axially measured viscoelastic recovery force from the UHMWPE fibres shows an initial rise and fall in output with time, equilibrium is reached after $\sim 3000 \mathrm{~h}$. These observations are attributed to fibre skin-core differences in viscoelastic properties, the skin regions possessing lower stiffness and longer term viscoelastic activity. Evidence from impact tests provides further support for these inferences.

(iii) In contrast with nylon 6,6 fibre-based VPPMCs, the increase in energy absorption from equivalent UHMWPE composites was maintained at the larger $(60 \mathrm{~mm})$ Charpy span setting; also energy absorption in absolute terms was 30-40\% higher for all (test and control) samples. We suggest that these effects emanate from the much greater stiffness of the UHMWPE fibres reducing the influence of the (brittle) matrix on fracture behaviour. 
Our findings are derived from tests on simple composite samples with unidirectional fibre reinforcement, restricted to a low $V_{\mathrm{f}}(3.6 \%)$. Although more extensive investigations are required, the current results suggest that the use of viscoelastically generated prestress in UHMWPE fibre-based composites may provide a means to improve impact toughness for various composite applications. Of a more general consequence is our evidence of energy absorption via the UHMWPE fibre skincore interface and whether this has wider implications for applications using such fibres.

\section{Acknowledgements}

The authors would like to thank Garry Robinson for technical support and Tony Sinclair for the EDX analysis. School of Engineering support (PhD degree fee waiver) for one of the authors (AF) is gratefully acknowledged.

\section{References}

[1] Fancey KS. Investigation into the feasibility of viscoelastically generated prestress in polymeric matrix composites. Mater Sci Eng A 2000; 279(1-2):36-41.

[2] Fancey KS. Prestressed polymeric composites produced by viscoelastically strained nylon 6,6 fibre reinforcement. J Reinf Plast Compos 2000; 29(15):12511266.

[3] Fancey KS. Fibre-reinforced polymeric composites with viscoelastically induced prestress. J Adv Mater 2005; 37(2):21-29.

[4] Pang JWC, Fancey KS. An investigation into the long-term viscoelastic recovery of Nylon 6,6 fibres through accelerated ageing. Mater Sci Eng A 2006; 431(12):100-105.

[5] Fancey KS. Viscoelastically prestressed polymeric matrix composites - Potential for useful life and impact protection. Compos Part B 2010; 41(6):454-461.

[6] Fazal A, Fancey KS. Viscoelastically prestressed polymeric matrix composites Effects of test span and fibre volume fraction on Charpy impact characteristics. Compos Part B 2013; 44(1):472-479.

[7] Pang JWC, Fancey KS. Analysis of the tensile behaviour of viscoelastically prestressed polymeric matrix composites. Compos Sci Tech 2008; 68(7-8):19031910.

[8] Pang JWC, Fancey KS. The flexural stiffness characteristics of viscoelastically prestressed polymeric matrix composites. Compos Part A 2009; 40(6-7):784-790.

[9] Hadi AS, Ashton JN. On the influence of pre-stress on the mechanical properties of a unidirectional GRE composite. Compos Struct 1998; 40(3-4):305-311.

[10] Motahhari S, Cameron J. Impact strength of fibre pre-stressed composites. J Reinf Plast Compos 1998; 17(2):123-130.

[11] Motahhari S, Cameron J. Fibre prestressed composites: improvement of flexural properties through fibre prestressing. J Reinf Plast Compos 1999; 18(3):279-288.

[12] Cui H, Guan M, Zhu Y, Zhang Z. The flexural characteristics of prestressed bamboo slivers reinforced parallel strand lumber (PSL). Key Eng Mater 2012; 517:96-100.

[13] Fazal A, Fancey KS. Viscoelastically generated prestress from ultra-high molecular weight polyethylene fibres. J Mater Sci 2013; 48(16):5559-5570. 
[14] Goodfellow Cambridge Ltd, UK. Online catalogue (material properties) at http://www.goodfellow.com; accessed August 2013.

[15] Alves ALS, Nascimento LFC, Suarez JCM. Influence of weathering and gamma irradiation on the mechanical and ballistic behavior of UHMWPE composite armor. Polym Test 2005; 24(1):104-113.

[16] Tissington B, Pollard G, Ward IM. A study of the influence of fiber resin adhesion on the mechanical behaviour of ultra-high-modulus polyethylene fiber composites. J Mater Sci 1991; 26(1):82-92.

[17] Silverstein MS, Breuer O. Mechanical properties and failure of etched UHMW PE fibers. J Mater Sci 1993; 28(15):4153-4158.

[18] Kakiage M, Tamura T, Murakami S, Takahashi H, Yamanobe T, Uehara H. Hierarchical constraint distribution of ultra-high molecular weight polyethylene fibers with different preparation methods. J Mater Sci 2010; 45(10):2574-2579.

[19] Abo El-Maaty MI, Olley RH, Bassett DC. On the internal morphologies of highmodulus polyethylene and polypropylene fibres. J Mater Sci 1999; 34:1975-1989.

[20] Riekel C, Cedola A, Heidelbach F, Wagner K. Microdiffraction experiments on single polymeric fibers by synchrotron radiation. Macromol 1997; 30:1033-1037.

[21] Pang JWC, Lamin BM, Fancey KS. Force measurement from viscoelastically recovering Nylon 6,6 fibres. Mater Lett 2008; 62(10-11):1693-1696.

[22] Costa L, Luda MP, Trossarelli L. Ultra high molecular weight polyethylene - II. Thermal and photo-oxidation. Polym Degrad Stab 1997; 58:41-54.

[23] Jacobson K. Oxidation of ultra high molecular weight polyethylene (UHMWPE) part 1: Interpretation of the chemiluminescence curve recorded during thermal oxidation. Polym Degrad Stab 2006; 91:2126-2132.

[24] Berger L, Kausch HH, Plummer CJG. Structure and deformation mechanisms in UHMWPE fibres. Polymer 2003; 44(19):5877-5884. 